\section{More on animal experiments}

SiR-Clive Hollands is to be commended for raising important issues regarding the responsibilities of scientific journals to uphold ethical standards regarding animal experimentation, (Nature 339, 248; 1989). Hollands specifically objected to Nature's publication of experiments, conducted in France, involving major surgery with anaesthesia on two pregnant macaque monkeys to remove bilaterally the eyes of two fetuses (Nature 337, 265-267; 1989). The fetuses were returned to the uterus and the pregnancies later terminated by caesarean section. The young monkeys were allowed to survive for some weeks and were then killed for tests to assess the influence of retinal input on cortical development. "Such gross interference with a highly intelligent species requires overwhelming justification - - if it can be justified", says Hollands. He considered these experiments would not be legal in the United Kingdom.

A subsequent leading article responded by stating that Nature's "rule of thumb" has been "that the results of animal experiments that would not easily win general regulatory consent had better be of exceptional interest if they are to be published" (Nature 339, 324; 1989). On two grounds, this is an inadequate response.

First, Nature gives no evidence that the criterion of "exceptional interest" is explicitly taken into account. Both the significance of the results and the trauma to the animal have to be identified in order to weigh the justification for conducting the experiments. The exceptional interest of retinal input on cortical development should not be assumed to be apparent to all readers.

Second, Nature's "rule of thumb" does not incorporate the concept that some procedures are beyond the pale irrespective of possible scientific merit. As Patrick Bateson, professor of ethology at the University of Cambridge, speaking for the animal ethical review committee of the journal Animal Behaviour has said, "If suffering was likely to be intense, we would not regard work as acceptable and would recommend rejection (for publication) even if the work was of high standard", (personal communication, 28 October 1985). He goes on to say: "Intermediate levels of suffering would be justified by high quality work. Low quality work would not justify any level of suffering and, in any event, would not be published in the journal anyway."

So how should journals handle manuscripts submitted for publication that appear to raise serious ethical issues? Should journals merely act as "passive entities", as John Maddox describes, leaving it up to the scientific community to make subsequent judgement (Nature 339 , $657 ; 1989)$ ? Or should journals assume an active role in helping to uphold high ethical standards? I believe the latter is the

Two pioneering journals have established commendable procedures for handling questionable animal experiments and have published meaningful and detailed policies on animal experimentation which appear in instructions to authors (Pain 12, 199; 1982 and Animal Behaviour 34, 315-318; 1986). The journals' manuscript reviewers are specifically charged with ensuring their compliance, and manuscripts identified as involving questionable animal experiments are referred to special committees for determination.

I do not have personal experience of serving on such a committee, but it seems to me that they could decide on one of several courses depending on the seriousness of the concern:

(1) reject the manuscript on humane grounds,

(2) require modification of the manuscript by the investigator for instance, to include any or all of the following: justification of the importance of the work; a description of the severity and duration of animal pain; a description of the procedures taken to alleviate the animals' suffering or

(3) publish the article with an editor's note drawing attention to the concerns (see, for instance, the editorial note that accompanied an article in Animal Behaviour 32, 293-294; 1984).

Publication of an article suggests scientific approval and tends to legitimize the work. It should be reserved for meritorious work that complies with the highest ethical standards of the day.

\section{F. BARBARA ORLANS}

7106 Laverock Lane,

Bethesda, Maryland 20817, USA

\section{A creative force?}

SiR-I am a scientist by training. I believe that an understanding of the Universe can be obtained only through careful observation. Models that allow us to comprehend observable phenomena can be constructed, but only when a model has been tested experimentally can it be held as truth. Nevertheless, I find myself flirting with explanations to problems that cannot be tested, knowing full well that until they can, I cannot allow myself to 'believe' in them as possible representations of truth.

My 'flirtation with the untestable' falls into two categories: phenomena that are occurring outside our time frame (such as the developmental diversification of life forms on Earth), and phenomena that responsible course occur within our time frame but seem to involve processes for which only the results are physically observable (such as 'human intelligence' and biological 'drive', and the 'experience' of them by the individual). I have no illusion that this flirtation with the untestable is anything other than religion, because the explanations my mind comes up with invariably involve an unknown, creative force. For a scientist, this is heresy. I should not be seeking to comprehend the Universe with untestable theories that postulate the existence of an unobservable 'force'. Untestable theories in science (such as the evolution of life through random diversification followed by natural selection), are permissible, but not if they involve forces from an unknowable source.

Ultimately, when I hold such beliefs, I must give up my scientist's persona and put on a religious one. For although I continue to use scientific truth to formulate a higher-resolution picture of the knowable Universe, I still find myself groping at 5,000-year-old untestable models. Instead of Adam and Eve, my creation myth begins in a 'primordial soup' with 'self-replicating molecules'. My struggle with the mystery of human consciousness uses terms such as 'mind-brain problem' and 'immanence illusion' rather than 'soul' or 'God'. I think in terms of 'creative and degradative' forces rather then forces of 'good and evil'. But when faced with the essential question - is there a creative force manifesting itself in the observable Universe? - I can answer yes, not with irreverence to any law of physics, but rather out of a sense of awe, in the face of utter bemusement.

A. TRAVIS

University of California, San Francisco, San Francisco,

California 94143, USA

\section{Nuclear power}

SIR-Although I was a signatory of the Greenpeace declaration on global warming, I nevertheless agree with Max Beran's strictures (Nature 340, 336; 1989). The text reached me about a week before it was due to be published and I immediately rang Greenpeace to say that I should be glad to sign but asked them to change "irrelevant" to something like "hardly relevant" or "little relevant". I was told that it was too late to make changes and I then signed. I should have declined, although I agreed with the declaration as a whole. Scientists should avoid using sweeping or emotional terms they cannot justify, even if they do so to correct a false and irresponsible ministerial statement.

N. KURTI

University of Oxford,

Department of Engineering Science,

Parks Road,

Oxford OX1 3PJ, UK 